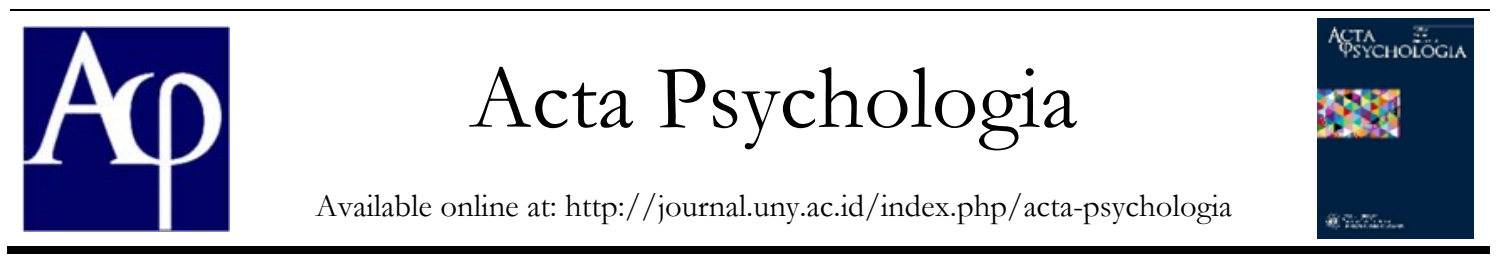

\title{
Pengaruh Dukungan Sosial Teman Sebaya terhadap Subjective Well-Being Pada Remaja yang Tinggal di Pondok Pesantren
}

\author{
Lufti Nooryan Sardi, Yulia Ayriza \\ Jurusan Psikologi, Universitas Negeri Yogyakarta; Jl. Colombo No. 1 Sleman Yogyakarta, 55281 \\ luftinoryan@gmail.com
}

\begin{abstract}
Abstrak
Subjecitive well-being merupakan hal penting yang perlu dimiliki oleh setiap remaja, namun masih ada remaja yang memiliki subjective well-bieng yang rendah. Tujuan penelitian ini adalah mengetahui pengaruh dukungan sosial dari teman sebaya terhadap subjective well-being pada remaja. Penelitian ini menggunakan pendekatan kuantitatif dengan jenis peneltian ex post facto. Sampel penelitian sebanyak 132 siswa SMA Ali-Maksum Yogyakarta yang ditentukan dengan teknik stratified random sampling. Penelitian ini menggunakan instrumen penelitian skala PANAS (positive affect and negative affect schedule) dan skala dukungan sosial teman sebaya. Uji validitas dalam penelitian ini menggunakan validitas isi dengan expert judgement, sedangkan reliabilitas menggunakan rumus Alpha Croncbach dengan nilia koefisien $\alpha 0,84$ pada skala PANAS dan life satisfaction, dan $\alpha 0,88$ untuk skala dukungan sosial teman sebaya Analisis data dilakukan dengan analisis deskriptif dan analisis regresi linear. Hasil penelitian menunjukkan bahwa terdapat pengaruh positif dukungan sosial teman sebaya terhadap subjective well-being pada remaja dengan nilai koefisien yang telah distandarisasi sebesar 0,306. Variabel dukungan sosial teman sebaya berkontribusi sebanyak $94 \%$ terhadap subjective well-being pada remaja.
\end{abstract}

Kata Kunci: dukungan sosial, subjective well-being

\begin{abstract}
Subjective well-being is a necessity to every teen, but in reality, there are teenagers who have low subjective wellbeing. Therefore, the purpose of this study is to determine the effect of social support from peers on subjective well-being in adolescents. Sample of this study is 132 students in Yogyakarta AliMaksum Islamic that were determined by using stratified random sampling technique. The instruments of this study are PANAS (Positive Affect and Negative Affect Schedule) and peer social support scale. The validity of the instruments were tested with content validity by expert judgment, meanwhile the reliability of the instruments were tested with alpha cronbach formula which then resulted in coeficient value of $\alpha 0,84$ on PANAS and life satisfaction as well as $\alpha$ 0,88 on peer social support scale. Data analysis is performed by using descriptive analysis and llinear regresion analysisThe finding of this study shows that there is a positive influence of peer social support on subjective wellbeing in adolescents with standardized coefficient value of 0.306 . Peer social support contributed $94 \%$ of subjective well-being in adolescents.
\end{abstract}

Keywords: peer social support, subjective well-being

\section{Pendahuluan}

Masa remaja merupakan masa di mana individu mengalami perubahan yang cepat dalam kehidupan. Hal ini disebabkan oleh perubahan biologis, kognitif, sosial serta emosional. Periode ini juga dikatakan sebagai masa transisi dari kanak-kanak menuju masa remaja (Karaman,
G.N, 2013:138). Banyak remaja saat ini memiliki waktu luang tanpa pengawasan orang tua, terutama pada sore hari. Biasanya, orang tua cenderung khawatir anak remajanya akan mendapat masalah di waktu-waktu ini. Bagi remaja, sore hari dihabiskan untuk kegiatan yang bersifat konstruktif, seperti kegiatan hobi, belajar, dan ekstrakurikuler yang berkaitan dengan 
sekolah. Namun, bagi remaja lainnya, waktu luang seperti itu menjadi kesempatan bagi mereka untuk bereksperimen dengan hal-hal yang berkaitan dengan perilaku seksual, kejahatan, atau bahkan penyalahgunaan zat (Sickmund, Snyder, \& Poe-Yamagata; Departemen Pendidikan \& Departemen Kehakiman A.S, dalam American Psychological Association, 2002:33).

Berdasarkan data dari survei Badan Narkotika Nasional (BNN) mengenai pengguna narkoba secara keseluruhan, ternyata $24 \%$ diantaranya adalah pelajar, dengan jumlah siswa dari tingkat Sekolah Dasar (SD) hingga Sekolah Menengah Atas (SMA) atau Sekolah Menengah Kejuruan (SMK) berjumlah 50 juta anak (tribunnews, selasa, 20 Desember 2018). Untuk menghindari perilaku negatif tersebut, orang tua cenderung memilih sekolah yang memiliki aturan yang lebih ketat, salah satunya adalah pondok pesantren.

Berada di pondok pesantren akan memberikan banyak pengalaman bagi para remaja, akan tetapi masih ada remaja yang menolak tinggal di pondok pesantren (Fadhillah, 2016:70). Sebuah kasus terjadi pada beberapa santri Pondok Pesantren Ali Maksum Yogyakarta yang mengaku bahwa merasa tidak betah dengan kehidupan pondok.

Subjective well being mengacu pada evaluasi afektif dan evaluasi kognitif pada kehidupan individu (Ed Diener 2000:34). Selanjutnya mengenai subjective well-being. Ed Diener, Oishi \& Lucas (2003:404) mengatakan bahwa kesejahteraan subjektif (SWB) terdiri dari serangkaian analisis ilmiah tentang bagaimana individu mengevaluasi hidup mereka, baik saat ini maupun di masa lalu. Evaluasi ini termasuk reaksi emosional individu terhadap peristiwaperistiwa dalam kehidupan, suasana hati, dan penilaian yang mereka bentuk mengenai kepuasan hidup mereka, pemenuhan, dan kepuasan dengan domain (bidang kehidupan) seperti persahabatan, pernikahan dan pekerjaan. subjective well- being merujuk pada fakta bahwa individu yang secara subjektif percaya bahwa hidupnya diinginkan, menyenangkan, dan baik (Ed Diener 2009:1).

Subjective well-being merupakan hal penting dan positif bagi remaja karena itu subjective well-being penting untuk dimiliki. Para peneliti subjective well-being telah mengaitkan kepuasan hidup dan afek positif sebagai komponen subjective wellbeing yang saling berhubungan (Diener 2009:13). Salah satu prediktor lain yang dapat dikaitkan dengan subjectice well-being adalah dukungan sosial. Ronen dan Seeman (2007:1060) dalam penelitiannya yang membahas tentang subjective well-being of adolescents in boarding schools under threat of war (kesejahteraan subyektif remaja di sekolah berasrama di bawah ancaman perang) mendapatkan hasil bahwa, dukungan sosial lebih pengaruh kuat dengan subjective well-being daripada keterampilan kontrol diri. Di sisi lain mereka juga mengatakan bahwa dukungan sosial dari teman sebaya mungkin bahkan lebih penting bagi remaja yang dikirim oleh orang tua mereka ke sekolah asrama akibat permasalahan di rumah.

Cobb (dalam Irwin, Sarason, dan Barbara 1985:4) mendefinisikan dukungan sosial sebagai informasi yang mengarahkan subjek untuk percaya bahwa ia dirawat dan dicintai. Shumaker dan Brawnell (1984) memberikan definisi dukungan sosial sebagai pertukaran sumber daya antara setidaknya dua individu yang dirasakan oleh penyedia atau penerima yang dimaksudkan untuk meningkatkan kesejahteraan penerima. Dukungan sosial mencakup keyakinan bahwa orang lain menyukai, menghargai, peduli dan ingin melakukan sesuatu dengan individu yang diberikan dukungan sosial. Remaja yang tidak mendapatkan dukungan sosial cenderung kurang memiliki sifat prososial (misalnya, membantu dan sopan), lebih tertekan secara emosional, dan memiliki nilai akademis lebih rendah (Wentzel dalam Sifers 2016:3). 
Tujuan penelitian ini adalah mengetahui pengaruh dukungan sosial dari teman sebaya terhadap subjective well-being pada remaja yang tinggal di pondok pesantren.

\section{Metode Penelitian}

Penelitian ini menggunakan pendekatan kuantitatif. Pendekatan kuantitatif digunakan kerena data yang diperoleh dalam penelitian ini berupa angka, kemudian akan dianalisi menggunakan metode statistika.

Penelitian ini berjenis penelitian ex post facto. Penelitian ex-post facto bertujuan menemukan penyebab yang memungkinkan perubahan perilaku, gejala atau fenomena yang disebabkan oleh suatu peristiwa, perilaku, gejala atau fenomena yang disebabkan oleh suatu peristiwa, perilaku atau hal-hal yang menyebabkan perubahan pada variabel bebas secara keseluruhan sudah terjadi (Dantes, 2012:60).

Penelitian ini bertempat di SMA AliMaksum Yogyakarta, Penentuan Tempat dipilih berdasarkan kesesuaian kriteria pada penelitian yang membutuhkan subjek remaja yang tinggal di pondok pesantren. Peneilitan ini dilaksanakan pada bulan Juli 2019 sampai dengan bulan November 2019.

Populasi dalam penelitian ini adalah santri putra dan putri Pondok Pesantren Ali Maksum kelas X, XI dan XII (sepulah, sebelas dan dua belas) yang sekolah di SMA Ali Maksum Yogyakarta, populasi di SMA Ali Maksum diketahui sebanyak 200 siswa.

Sampel merupakan perwakilan dari populasi (Dantes, 2012:38). Sampel dalam penelitian ini adalah para santri Pondok Pesantren Ali Maksum Yogyakarta kelas X-XII (kelas sepuluh sampai kelas dua belas) yang sekolah di SMA Ali Maksum Yogyakarta, pengambilan sampel menggunakan teknik probability sampling dengan jenis stratified random sampling.
Teknik pengumpulan data dalam penelitian ini menggunakan metode skala, untuk variabel subjective well-being menggunakan skala panas dan life satisfaction, sedangkan pada variabel dukungan sosial temna sebaya, menggunkan skala dukungan teman sebaya.

Penelitian ini mengunakan validitas isi yag mengacu pada diestimasi lewat pengujian terhadap kelayakan atau relevansi isi tes melalui analisis rasional oleh panel yang berkompeten atau melalui expert judgment (Azwar, 2018: 42). Nilai keoefisien reliabilitas skala $P A N A S$ dan life satisfaction berada pada rentang nilia 0,86 0,90, sedangankan nilai koefiesien reliabilitas pada skala dukungan sosial teman sebaya sebesar 0,88 .

Teknik analisis data yang digunakan dalam penelitian ini meliputi analisis deskriptif dan uji prasyarat analisis data yang terdiri dari uji normalitas dan uji linearitas; serta uji hipotesis statistik.

\section{Hasil Penelitian}

Berdasarkan hasil deskriptif kategorisasi variabel subjective well-being diperoleh data sebagai berikut:

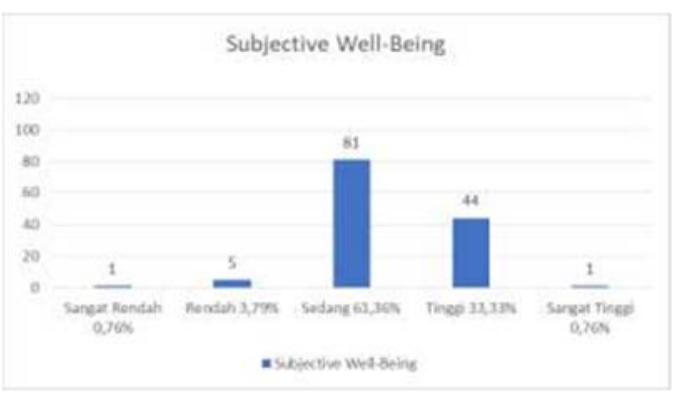

Gambar 1. Diagram Subjective Well-Being

Berdasarkan data dari Gambar 1, dapat diketahui bahwa tingkat subjective wellbeing pada remaja yang tinggal di pondok pesantren pada tingkat kategori sangat rendah diketahui sebanyk 1 siswa $(0,76 \%)$, tingkat kategori rendah sebanyak 5 siswa $(3,79 \%)$, tingkat kategori sedang sebanyak 81 siswa $(61,36 \%)$, tingkat kategori tinggi 
sebanyak 44 siswa $(33.33 \%)$, dan tingkat kategori sangat tinggi sebanyak 1 siswa $(0.76 \%)$. Berdasarkan data ini dapat dismpulkan bahwa mayoritas subjek berapa pada kategori sedang yaitu sebanyak 81 siswa $(61,36 \%)$ dari total sampel 132 siswa.

Berdasarkan hasil deskriptif kategorisasi variabel dukungan sosial teman sebaya diperoleh data sebagai berikut:

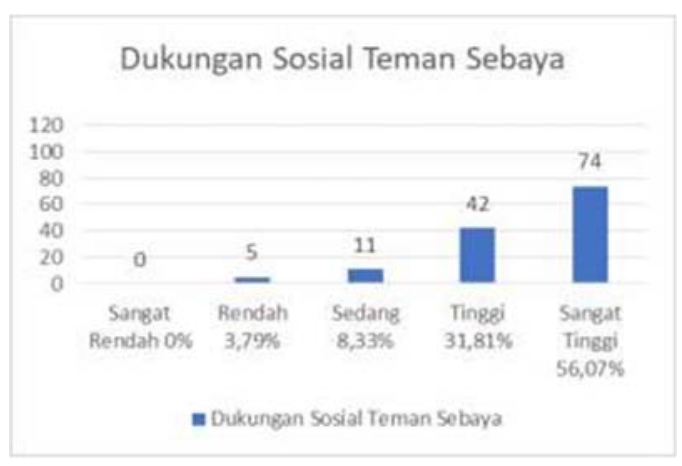

Gambar 2. Dukungan Sosial Teman Sebaya

Berdasarkan Gambar 2, dapat diketahui bahwa kategorisasi dukungan sosial teman sebaya pada tingkat sangat rendah dengan jumlah 0 siswa $(0 \%)$, pada tingkat rendah dengan jumlah 5 siswa (3,79\%), pada tingkat sedang dengan jumlah 11 siswa (8,33\%), pada tingkat tinggi dengan jumlah 42 siswa $(31,81 \%)$, dan pada tingkat sangat tinggi dengan jumlah 74 siswa (56,07\%). Berdasarkan data ini dapat disimpulkan juga bahwa mayoritas subjek berada pada kategori sangat tinggi dengan jumlah siswa sebanyak 74 orang $(5607 \%)$ dari total sampel sebanyak 132 siswa.

Uji normalitas bertujuan untuk menguji sebaran data yang akan dianalisis berdistribusi normal atau tidak. Uji normalitas menggunakan uji KolmogorovSmirnov dengan $\square=0,05$ dengan bantuan program SPSS for Windows. Data yang berdistribusi normal memiliki $\square$ Q 0,05, dalam penelitian ini nilai signifikansi sebesar 0,935 lebih besar dari 0,05.

Analisis regresi sederhana digunakan untuk mengukur pengaruh variabel dukungan sosial teman sebaya dan variabel subjective well being.

Tabel 1. Hasil Uji Regresi Linier Sederhana

\begin{tabular}{|c|c|c|c|c|c|}
\hline \multirow[t]{2}{*}{ Model } & $\begin{array}{r}\text { Unsta } \\
z \\
\text { Coeff }\end{array}$ & $\begin{array}{l}\text { Indardi } \\
\text { ed } \\
\text { icients }\end{array}$ & $\begin{array}{l}\text { Standardi } \\
\text { zed } \\
\text { Coefficien } \\
\text { ts }\end{array}$ & \multirow[t]{2}{*}{ i } & \multirow[t]{2}{*}{ Sig. } \\
\hline & B & $\begin{array}{l}\text { Std. } \\
\text { Error }\end{array}$ & Beta & & \\
\hline \multicolumn{2}{|c|}{1 Consti $_{9}^{65,22}$} & 4,81 & \multirow{2}{*}{,306 } & $\begin{array}{l}13,5 \\
52\end{array}$ & ,00 \\
\hline SS & 284 & ,07 & & $3,66:$ & ,00 \\
\hline
\end{tabular}

Berdasarkan hasil analisis data pada tabel 1, dukungan sosial teman sebaya memiliki nilai signifikan 0,306 dengan nilai signifikansi $0,00<0,005$, maka dapat dikatakan bahwa variabel dukungan sosial teman sebaya menunjukan signifikansi. Hasil perhitungan pada Tabel 1 juga memperoleh hasil nilai konstanta (a) sebesar 65,229 dan nilai regresi prediktor (b) sebesar 0,306. Secara umum rumus persamaan regresi adalah $(\mathrm{Y}=\mathrm{a}+\mathrm{bX})$ maka diperoleh persamaan regresi $\mathrm{Y}=$ $65,229+(0,306 \mathrm{X})$ yang berarti jika nilai $\mathrm{X}$ telah diketahui maka nilai $Y$ dapat diketahui dengan mengalikan nilai $\mathrm{X}$ dengan nilai koefisien regresi $(0,306)$ yang kemudian dijumlahkan dengan nilai konstanta $(65,229)$.

\section{Pembahasan}

Berdasarkan hasil analisis kategorisasi variabel subjective well-being pada remaja yang tinggal di pondok pesantren diketahui sebanyak 1 siswa $(0,76 \%)$ termasuk dalam kategori sangat tinggi, 44 siswa $(33,33 \%)$ berada pada kategori tinggi, 81 siswa $(61,36)$ berada pada kategori sedang, 5 siswa $(3,79 \%)$ berada pada kategori rendah, dan 1 siswa $(0,76 \%)$ 
berada pada kategori sangat rendah (lihat Tabel 6). Berdasarkan data tersebut dapat disimpulkan bahwa mayoritas subjek memiliki tingkat subjective well-being yang sedang. Diener (dalam Eid dan Larsen, 2008) mengatakan bahwa subjective well-being pada tingkat sedang menandakan belum optimalnya subjective well-being pada diri individu, sehingga perlu ditingkatkan lagi.

Mayoritas subjek yang berada pada kategori sedang dikarenakan skor afek negatif $(34,83 \%)$ tidak berbeda jauh dengan skor afek kepuasan hidup $(24,03)$ dan skor afek positif $(41,14)$ (lihat Tabel 7). Diener dkk (Diener, Oishi, dan Lucas, 2012) mengatakan bahwa subjective well-being merupakan hasil evaluasi kognitif dan afektif seseorang terhadap kehidupan yang dijalaninya yang terdiri atas aspek afektif (afek positif dan afek negatif) serta aspek kognitif (kepuasan hidup). Subjek dikatakan memiliki subjective well-being yang tinggi apabila subjek tersebut lebih sering mengalami afek positif daripada afek negatif dalam hidupnya dan memiliki kepuasan hidup yang tinggi. Subjek yang memiliki subjective well-being yang tinggi dapat menjalani hubungan yang dekat dengan kehidupan sosialnya, dibandingkan dengan orang-orang yang memiliki subjective well-being yang rendah (Eid \& Larsen, 2008).

Hasil analisis kategorisasi pada variabel dukungan sosial teman sebaya diketahui bahwa sebanyak 74 siswa (56.07\%) termasuk dalam kategori sangat tinggi, 42 siswa $(31.81 \%)$ berada pada kategori tinggi, 11 siswa (8.33) berada pada kategori sedang, 5 siswa $(3.799 \%)$ berada pada kategori rendah, dan 0 siswa $(0 \%)$ berada pada kategori sangat rendah (lihat Tabel 9). hal itu menunjukan bahwa myoritas subjek memiliki dukungan sosial teman sebaya yang tinggi. Cobb (dalam Irwin, Sarason, dan Barbara 1985:4) mengatakan bahwa memiliki dukungan sosial yang tinggi berarti individu merasa dirinya dirawat dan dicintai. dukungan sosial merupakan hal yang penting bagi remaja karena apabila remaja tidak memiliki dukungan sosial atau pertemanan yang berarti hal ini akan menyebabkan penyesuaian psikologis yang rendah dan meningkatkan risiko masalah-masalah psikologis pada masa dewasa (Seymour, 2017:17).

Data perolehan skor aspek dukungan sosial teman sebaya menunjukan bahwa remaja yang tinggal di pondok pesantren lebih dominan merasakan aspek dukungan harga diri $(36,64 \%)$. Hal ini berarti remaja yang tinggal di pondok pesantren lebih merasa mendapatkan dukungan ketika teman sebayanya menunjukan perhatian terhadap keterampilan dan kemampuannya, menunjukan ekspresi yang meggambarkan penghargaan positif kepada dirinya dan memberikan perbandingan yang positif antara dirinya dengan orang lain, yang kemampuannya kurang baik dari dirinya sendiri (Cohen dan Syme, dalam Indrawati, 2017:90).

Hasil uji hipotesis pada penelitian ini membuktikan bahwa ada pengaruh positif yang signifikan antara dukungan sosial teman sebaya dengan subjective well-being pada remaja. Berdasarkan hasil tersebut, maka terbukti bahwa hipotesis penelitian diterima (lihat Tabel 14). Hal tersebut dapat dilihat dari hasil koefisien regresi yaitu sebesar 0,306 dengan nilai $\square=0,000$ $(\square<0,05)$. Koefisien regresi bernilai positif, artinya dukungan sosial teman sebaya secara positif memprediksi subjective well-being pada remaja.

Dukungan sosial merupakan pertolongan dan dukungan yang diperoleh seseorang dari interaksinya dengan orang lain, dimana bantuan tersebut akan dapat menaikkan perasaan positif serta mengangkat harga diri sehingga akan berdampak pada kesejahteraan individu secara umum (Bishop, dalam Poegoeh \& Hamidah, 2016). Dukungan sosial juga dapat mengurangi perilaku dan emosi negatif, serta mereduksi tingkat stress (Ryff, dalam Raharjo \& Sumargi, 2018), selain itu Dukungan sosial berperan 
penting untuk membantu individu memperoleh kepercayaan dirinya sehingga individu tersebut dapat menghadapi situasi yang menekan Dengan adanya dukungan sosial dari lingkungan sekitar, remaja menjadi lebih tahan terhadap stres dan lebih memiliki rasa percaya diri dalam menghadapi tantangan, hal inilah yang kemudian berdampak juga pada kepuasan hidupnya (Brannon \& Feist, 2010).

Hasil perolehan data tersebut sejalan dengan penelitian yang dilakukan Ronen dan Seeman (2007:1060) dalam penelitiannya yang membahas tentang subjective well-being of adolescents in boarding schools under threat of war (kesejahteraan subyektif remaja di sekolah berasrama di bawah ancaman perang) mendapatkan hasil bahwa, dukungan sosial lebih berpengaruh kuat dengan subjective well-being daripada keterampilan kontrol diri, di sisi lain mereka juga mengatakan bahwa dukungan sosial dari teman sebaya mungkin bahkan lebih penting bagi remaja yang dikirim oleh orang tua mereka ke sekolah asrama akibat permasalahan di rumah.

Perolehan hasil nilai koefisien determinan (R Square) sebesar 0,94, (lihat lampiran 6) hal ini menunjukkan bahwa variabel dukungan sosial teman sebaya mampu memprediksi variabel subjective wellbeing pada remaja, dengan memberikan sumbangan efektif sebesar 94\%. Hasil tersebut sesuai dengan teori yang disampaikan oleh. Amalia (2014) yang menjelaskan bahwa dukungan sosial memiliki pengaruh positif langsung yang signifikan dengan subjective well-being. dalam penelitian tersebut faktor determinan dukungan sosial memiliki persentase sebesar 42,95\%. Berdasarkan penelitian ini juga diketahui bahwa terdapat $6 \%$ faktor lain yang dapat mempengaruhi subjective well-being selain dukungan sosial teman sebaya. faktor lain tersebut adalah pendapatan, religiusitas, kebersyukuran, dan kepribadian, Diener (dalam Rakhman, Tentama, Situmorang, 2018:16) juga mengatakan bahwa kepribadian merupakan hal yang berpengaruh pada subjective wellbeing. Hal ini dikarenakan beberapa variabel kepribadian menunjukkan kekonsistenan dengan subjective well-being.

Remaja yang mendapatkan dukungan sosial dari teman sebayanya akan merasa disayangi, diperhatikan, dan dipedulikan oleh teman sebayanya (Ginting, 2015:5) dengan begitu, remaja akan mengembangkan sikap yang positif dan memiliki subjective well-being yang tinggi. Remaja yang memiliki subjective wellbeing akan dapat berfungsi secara positif dalam mencapai aktualisasi diri dan menjalankan tahapan perkembangannya, yang tidak mendapatkan dukungan sosial dari teman sebayanya akan merasa tidak berguna, tidak ada seseorang yang peduli dengannya, dan melihat dirinya secara negatif dan menyebabkan subjective well-being yang rendah.

Terbuktinya hipotesis dalam penelitian ini dapat memberikan informasi bahwa dukungan sosial teman sebaya dapat memprediksi suvjective well-being pada remaja yang tinggal di pondok pesantren, oleh karena itu dukungan sosial teman sebaya yang tinggi perlu dimiliki oleh remaja yang tinggal di pondok pesantren agar dapat memliki subjective well-being yang tinggi pula.

\section{Simpulan dan Saran}

Berdasarkan hasil penelitian, diketahui bahwa terdapat hubungan yang positif antara dukungan sosial teman sebaya dengan subjective well-being pada remaja. hal ini menjelaskan bahwa dukungan sosial teman sebaya dapat menjadi prediktor terhadap subjective wellbeing pada remaja. Besarnya kontribusi dukungan sosial teman sebaya dalam mempengaruhi subjective well-being pada remaja yang tinggal di pondok pesantren sebesar $94 \%$ dan sisanya $6 \%$ dipengaruhi oleh variabel lain. Simpulan dapat bersifat generalisasi temuan sesuai permasalahan 
penelitian, dapat pula berupa rekomendatif untuk langkah selanjutnya.

Berdasarkan hasil penelitian, terdapat beberapa saran yang dapat dilakukan bagi remaja dan guru.

Bagi remaja, perlu meningkatkan kesadaran akan pentingnya menjalin hubungan yang dekat dengan teman sebayanya serta saling memberi dukungan antar teman.

Bagi guru bimbingan dan konseling, perlu meningkatkan kesadaran siswa tentang pentingnya memberikan dukungan sosial kepada sesama teman sebayanya, mengajarkan kepada para siswa untuk dapat mengelola emosi dengan baik agar dapat terhindar dari emosi-emosi negatif yang mengurangi tingkat kesejahteraan.

\section{Daftar Pustaka}

Adicondro, N., dan Alfi Purnamasari. (2011). Efikasi diri, dukungan sosial keluarga, dan self regulated learning pada siswa kelas VIII. Jurnal Humanitas, 8 (1), 17-27.

American Psychology Asociation. (2002) Developing Adolscents, Washinton DC. American Psychology Asociation. Diakses dari http://www.apa.org/pi/families/res ources/de velop.pd pada tanggal 11 Maret 2018.

Ayriza, Y., Setiawati, F. A., Nurhayati, S. R., Gumelar, S. R., Sholeha, S. P. D. R. (2019). Does Sleep Quality Serve as a Mediator Between Well-Being and Academic Achievement?. Cakrawala Pendidikan 38(1), 63-74.

A'yun, M, Q., Tentama, F., Situmorang, N, Z. (2018) Gambaran Subjective WellBeing pada Remaja Perempuan di Pondoke Pesantren. Diakses dari http://eprints.uad.ac.id/11149/ pada Tanggal 11 Maret 2019.

Azwar, S. (2015). Validitas dan reliabilitas (edisi 4). Yogyakarta: Pustaka Pelajar. (2018). Metode penelitian
Psikologi. Yogyakarta: Pustaka Pelajar.

Bakry, S. (2005) Mengagas Ilmu Pendidikan Pendidikan Islam. Bandung. Pustaka Bani Quraisy.

Brannon, L., \& Feist, J. (2010). Health psychology. Canada: Wadsworth Cengage Learning.

Diener, E. (2000). Subjective Well-Being The Science of Happiness annd a Proposal for a National Index. Amerika.

Diener, E. (2009). The Science of WellBeing The Collected Works of Ed Diener. New York. Springer.

Diener, E. ; Oishi, S. \& Lucas, R. E. (2003). Personality Culture, And Subjective Well Being: Emotional And Cognitive Evaluation of Life.Annual Review of Psychology, 54, 403-425.

Eid, Michael., Larsen, R, J (2008) The Science of Subjective Well-Being. New York. The Guildford Press.

Fadhillah, E, P, A. (2016) Hubungan Antara Psychologicall Well-Being dan Happiness pada Remaja di Pondok Pesantren. Jurnal Ilmiah Psikologi Volume 9, No 1.

Ginting, D.C.E. (2015). Dukungan sosial orangtua, pengasuh panti, dan teman sebaya sebagai prediktor terhadap kesejahteraan psikologis pada remaja yang tinggal di Panti Asuhan di Boyolali. Skripsi. Fakultas Psikologi. Universitas Kristen Satya Wacana Salatiga.

Hamdana Fara., Alhamdu. (2015) Subjective Well-Being Siswa MAN 3 Palembang yang Tinggal di Asrama. Jurnal Psikologi Islami Vol. 1 No. 1 95-104. Diakses dari http://jurnal.radenfatah.ac.id/index. $\mathrm{php} / \mathrm{psik}$ is/article/view/560/498 pada Tangga 11 Maret 2019.

Indrawati, Triana. (2017). Peranan kecerdasan emosi dan dukungan 
sosial terhdap kesejahteraan psikologis siswa SMP Terbuka di Cirebon. Jurnal Edukasia Islamika, 2, (1),. 77-103.

Karaman, Neslihan G (2013) Predicting The Problem Behavior in Adolescents. Eurasian Journal of Education Research, Issue, 137-154. Diakses dari https://pure.royalholloway.ac.uk/po rtal/files/

25415316/Seymour Natalie Psycho logical

Well beinginadolescents Planningto warda ndthinkingaboutthefuture.pdf Pada tanggal 11 Maret 2018.

Lestari, Veronica. (2016). Hubungan antara dukungan sosial orangtua dengan penyesuaian diri remaja dengan orangtua bercerai. Skripsi. Fakultas Psikologi. Universitas Sanata Dharma Yogyakarta.

Lutfi, D.N. (2012). Hubungan antara dukungan teman sebaya dengan kemampuan pemecahan masalah pada santriwati pengurus Organisasi Pelajar PPMI Assalaam (OP3MIA). Skripsi. Fakultas Psikologi. Universitas Muhammadiyah Surakarta.

Maddux, James E. (2018). Subjective WellBeing and Life Satisfaction. New York. Routledge.

Ni'mah, Ainun. (2014). Hubungan antara dukungan sosial dengan self efficacy dalam menyelesaikan skripsi pada mahasiswa jurusan bimbingan dan konseling universitas negeri semarang angkatan tahun 2009. Skripsi. Fakultas Ilmu Pendidikan. Universitas Negeri Semarang.

Park, Nansook. (2004) The Annals of The American Academy of Political and Social Science. New York. Sage.

Pierce, G, R., Barbara R., Sarason., Irwin, G. (1985). Handbook of Social Support and The Family. New York. Springer.
Papalia, Diane E. \& Feldman, Ruth Duskin. 2015. Experience Human Development. Buku 1. Edisi 12. Jakarta: Salemba Humanika.

Puspitasari, Y.P., Abidin, Z., dan Savitri, D.R. (2010). Hubungan antara dukungan sosial teman sebaya dengan kecemasan menjelang ujian nasional (UN) pada siswa kelas XII regular SMA Negeri 1 Surakarta. Tesis. Universitas Diponegoro.

Ristianti, Amie. (2012). Hubungan antara dukungan sosial teman sebaya dengan identitas diri pada remaja di SMA Pusaka 1 Jakarta. Skripsi. Fakultas Psikologi. Universitas Gunadarma.

Roger J.R., Levesque. (2016) Encyclopedia of Adolescence. New York. Springer

Ronen, T. Seeman, A (2007). Subjective WellBeing of Adolescents in Boarding School Under Threat of War. Journal of Traumatic Stress, Vol 20 No 06.

Ryff, C. D. (1989). Happiness is everything, or is it? Explorations on the meaning of psychological wellbeing. Journal of Personality \& Social Psychology, 57, 10691081. doi: 10.1037/0022-3514.57.6.1069. 